\title{
Đổi mới sáng tạo: phép màu thành công của doanh nghiệp
}

\author{
CESTI \\ Bộ Khoa học và Công nghệ \\ May 19, 2014 \\ URL:
}

https://cesti.gov.vn/bai-viet/su-kien-khcn/doi-moi-sang-tao-phep-mauthanh-cong-cua-doanh-nghiep-01001974-0000-0000-0000-000000000000

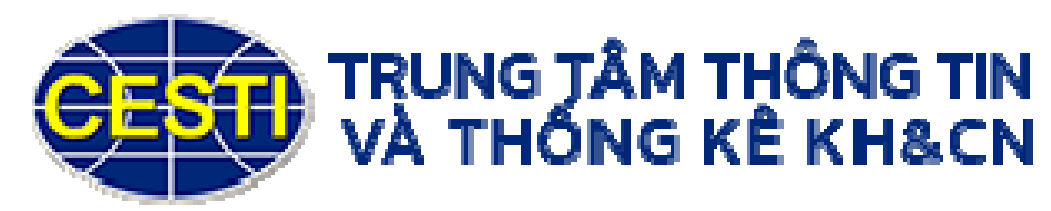




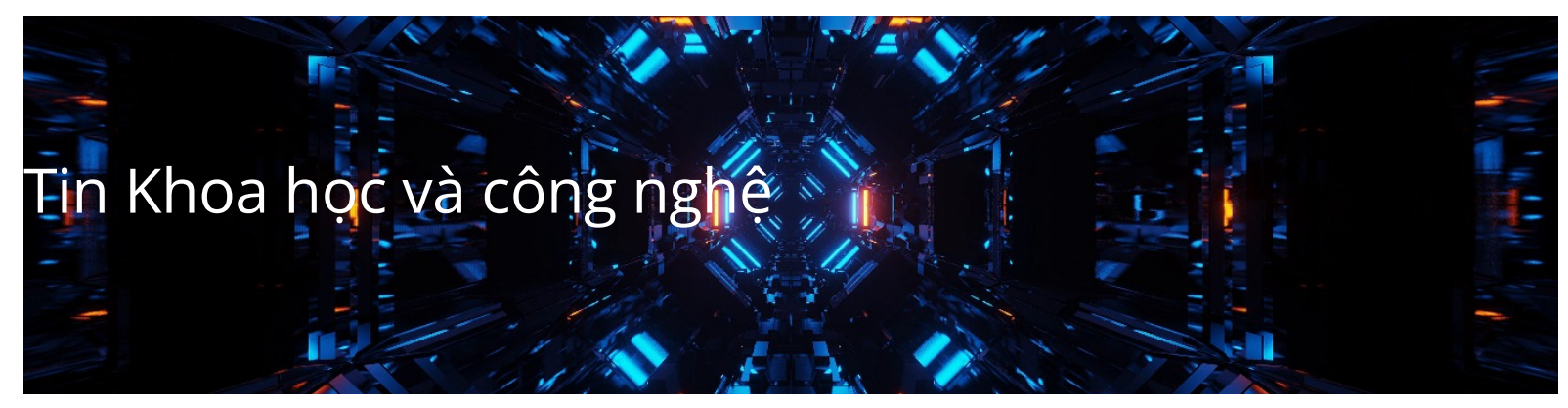

\title{
Đổi mới sáng tạo: phép màu thành công của doanh nghiệp
}

\author{
Hoạt động KH\&CN 19/05/2014 \\ Lượt xem: 1049 Lượt thích: 0 B
}

Đó là chủ đề của Diễn đàn Quốc tế về kinh doanh sáng tạo lần 1 (International Innovation Business Forum - IIBF) do Hội Doanh nghiệp Hàng Việt Nam chất lượng cao phối hợp cùng Bộ Khoa học \& Công nghệ tổ chức tại TP. HCM ngày 16/5/2014.

Đó là chủ đề của Diễn đàn Quốc tế về kinh doanh sáng tạo lần 1 (International Innovation Business Forum - IIBF) do Hội Doanh nghiệp Hàng Việt Nam chất lượng cao phối hợp cùng Bộ Khoa học \& Công nghệ tổ chức tại TP. HCM ngày $16 / 5 / 2014$.

Diễn đàn quy tụ các diễn giả là chính khách, chuyên gia, doanh nghiệp quốc tế đến từ Hoa Kỳ, Thụy Sİ, Nhật Bản, Israel, Singapore, Thái Lan và các doanh nghiệp hàng đầu Việt Nam về đổi mới sáng tạo như Thiên Long, Rạng Đông, An Phú Đà Lạt (làng rau thần kỳ).

Tại diễn đàn, các diễn giả chia sẻ ba nhóm chủ đề chính: kinh nghiệm xây dựng môi trường khuyến khích đổi mới sáng tạo của các quốc gia hàng đầu về công nghệ; kinh nghiệm xây dựng chiến lược và hoạt động đổi mới sáng tạo thành công của các doanh nghiệp quốc tế; kinh nghiệm của các doanh nghiệp hàng đầu Việt Nam về đổi mới sáng tạo, và những kiến nghị chính sách đối với cơ quan quản lý Nhà nước.

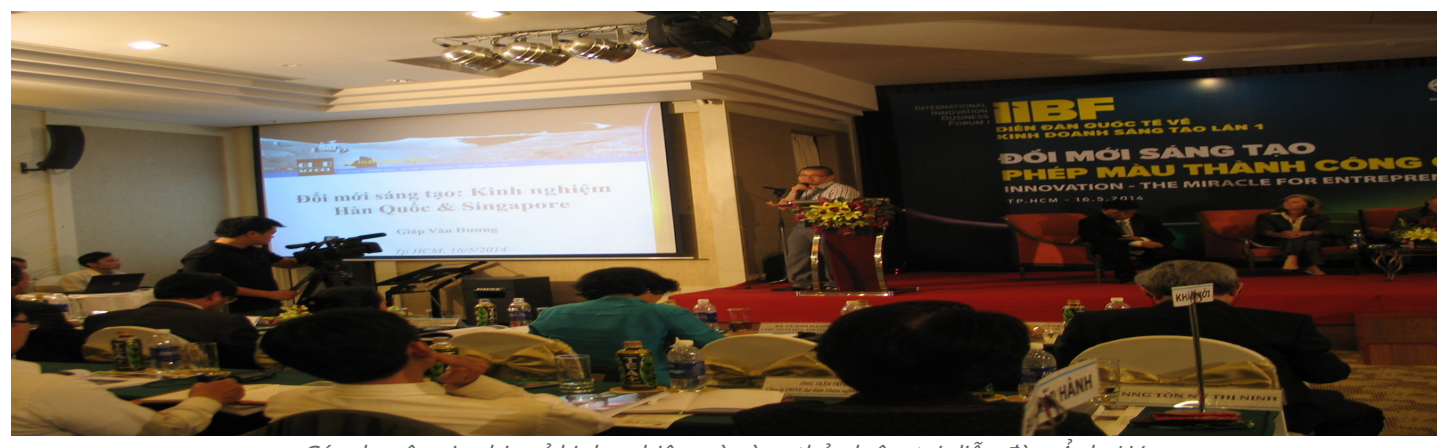

Các chuyên gia chia sẻ kinh nghiệm và cùng thảo luận tại diễn đàn. Ảnh: LV.

Cũng tại Diễn đàn này, Trung tâm Nghiên cứu kinh doanh và hỗ trợ doanh nghiệp (BSA) và DHVP Reasearch \& Consultancy đã công bố kết quả khảo sát i2Metrix (bộ chỉ số đo lường năng lực đổi mới - sáng tạo - cạnh tranh của doanh nghiệp) năm 2014 trên 19 doanh nghiệp dẫn đầu. Từ bộ đo đổi mới sáng tạo i2Metrix, các chuyên gia của BSA và DHVP qua phỏng vấn sâu các doanh nghiệp đã có một phát hiện thú vị là không nhất thiết phải nhiều tiền mới có thể nghĩ đến đổi mới sáng tạo. 
doanh sáng tạo lần thứ nhất" nhằm trao đổi thông tin, tìm hiểu kinh nghiệm từ các quốc gia, thể chế đổi mới sáng tạo thành công; chia sẻ bí quyết thực hành đổi mới sáng tạo trong kinh doanh của doanh nghiệp, tìm ra những giải pháp hỗ trợ căn cơ cho doanh nghiệp nâng cao năng lực sáng tạo (như việc ứng dụng bộ tiêu chí đo năng lực đổi mới sáng tạo i2Metrix); để cuối cùng đưa ra các kiến nghị thiết thực với nhà nước và các viện trường, nhằm tạo bước chuyển biến có giá trị trong ứng dụng khoa học công nghệ vào sản xuất kinh doanh. IIBF cũng là hoạt động hưởng ứng ngày Khoa học và Công nghệ Việt Nam lần đầu tiên (18/5).

Lam Vân

Từ khóa: lamvan-skkhcn đổi mới sángtạo doanh nghiệp 


\section{Tin khác}

Hội thảo "Xu hướng côngnghệ̣ xử lý rác thải điện tử” (15/10/2021)

Khai mở,_phát triển chính phủ số, kinh tế số, xã hội số trên phạm vi toàn cầu (13/10/2021)

Techmart Công nghệ sau thu hoạch 2021: tham quan và tương tác trực tuyến (12/10/2021)

Techfest Việt Nam 2021: Một diện mạo mới(12/10/2021)

Doanh nghiệp công nghệ thông tin Việt Nam: Đóng vai trò then chốt trong công cuộc chuyển đổi số $(12 / 10 / 2021)$

Xem thêm

\section{TRUNG TÂM THÔNG TIN VÀ THỐNG KÊ KH\&CN TP.HCM}

Địa chỉ: 79 Trương Định, Quận 1, TP.HCM

Tel: 84-28-38297040 (84-28-38256320)

Fax: 84-28-38291957

E-mail: cesti@cesti.gov.vn

Website: cesti.gov.vn

Facebook: https://www.facebook.com/CESTI.VN

Giấy phép thiết lập Trang thông tin điện tử tổng hợp số 89/GP-TTĐT do STT\&TT cấp ngày 09/11/2018 
